\title{
Crystal structures of an unmodified bacterial tRNA reveal intrinsic structural flexibility and plasticity as general properties of unbound tRNAs
}

\author{
CLARENCE W. CHAN, DEANNA BADONG, RAKHI RAJAN, ${ }^{1}$ and ALFONSO MONDRAGÓN
}

Department of Molecular Biosciences, Northwestern University, Evanston, Illinois 60208-3500, USA

\begin{abstract}
Ubiquitous across all domains of life, tRNAs constitute an essential component of cellular physiology, carry out an indispensable role in protein synthesis, and have been historically the subject of a wide range of biochemical and biophysical studies as prototypical folded RNA molecules. Although conformational flexibility is a well-established characteristic of tRNA structure, it is typically regarded as an adaptive property exhibited in response to an inducing event, such as the binding of a tRNA synthetase or the accommodation of an aminoacyl-tRNA into the ribosome. In this study, we present crystallographic data of a tRNA molecule to expand on this paradigm by showing that structural flexibility and plasticity are intrinsic properties of $t R N A s$, apparent even in the absence of other factors. Based on two closely related conformations observed within the same crystal, we posit that unbound tRNAs by themselves are flexible and dynamic molecules. Furthermore, we demonstrate that the formation of the T-loop conformation by the tRNA TYC stem-loop, a well-characterized and classic RNA structural motif, is possible even in the absence of important interactions observed in fully folded tRNAs.
\end{abstract}

Keywords: tRNA; structure; X-ray crystallography; flexibility; T-loop

\section{INTRODUCTION}

Ribosomes in all living systems depend universally on transfer RNA (tRNA) molecules to incorporate the amino acid sequence encoded by messenger RNA transcripts during translation and this decoding process forms the physical basis of the genetic code (Ramakrishnan 2002). Given their vital role in cellular metabolism, tRNAs are not only highly abundant in cells, but also tightly regulated throughout their life cycle (El Yacoubi et al. 2012; Kirchner and Ignatova 2015; Roundtree et al. 2017). The biogenesis of tRNAs is a complex process whose details are still not fully understood; however, across all domains of life conserved mechanisms dictate that tRNAs are synthesized as precursor molecules that undergo a series of activating post-transcriptional modifications for subsequent aminoacylation and thus recruitment by the ribosome (Phizicky and Hopper 2010).

The physiological importance of tRNAs has prompted numerous studies in recent decades to examine closely

\footnotetext{
${ }^{1}$ Present address: Department of Chemistry and Biochemistry, Price Family Foundation Institute of Structural Biology, Stephenson Life Sciences Research Center, University of Oklahoma, Norman, Oklahoma 73019-5251, USA

Corresponding author: a-mondragon@northwestern.edu

Article is online at http://www.rnajournal.org/cgi/doi/10.1261/rna. 073478.119.
}

the structure-function relationships exhibited by tRNAs both in isolation and in complex with other macromolecular entities (Korostelev and Noller 2007; Fei et al. 2011; Agirrezabala and Valle 2015; Marín et al. 2017). Although a substantial amount of structural data have been obtained for many larger and seemingly more complex non-coding RNAs ever since the elucidation of the first tertiary structures of tRNA in the 1970s (Kim et al. 1974; Robertus et al. 1974), tRNAs remain as prototypical molecules for RNA structural studies (Shi and Moore 2000). In fact, a significant amount of information relating to base pairing, base stacking, base modifications, and additional tertiary elements that facilitate long-range intramolecular interactions in folded RNAs were first identified and analyzed in detail in tRNA crystal structures (Batey et al. 1999; Moore 1999; Shi and Moore 2000; Hendrix et al. 2005).

In this study, we present crystallographic data derived from an unmodified Escherichia coli tRNA ${ }^{\text {Asp }}$ produced by in vitro transcription that further support the notion that structural flexibility and plasticity are inherent

\footnotetext{
(c) 2020 Chan et al. This article is distributed exclusively by the RNA Society for the first 12 months after the full-issue publication date (see http://rnajournal.cshlp.org/site/misc/terms.xhtml). After 12 months, it is available under a Creative Commons License (Attribution-NonCommercial 4.0 International), as described at http:// creativecommons.org/licenses/by-nc/4.0/.
} 
properties of its structure. Although conformational flexibility is by now a well-established and assumed trait of tRNA tertiary structure, prior observations of this characteristic have been made typically in the context of an inducing agent or event, such as the binding of a tRNA synthetase or the accommodation of an aminoacyl-tRNA into the ribosome (e.g., Agirrezabala and Valle 2015; Kuhn 2016). Even when comparative analyses were conducted on free, full-length tRNAs, apparent differences in conformation were attributed generally to sequence variation, solvent conditions, or nucleobase modifications (Byrne et al. 2010). In the current paradigm of RNA structural biology, tRNAs are generally regarded as rigid, two-domain, Lshaped molecules that adaptively undergo conformational change principally in response to the action of other molecular entities (Dethoff et al. 2012). Here we propose that tRNAs are intrinsically flexible and dynamic molecules, which likely sample, without provocation, a wider range of conformational states than previously thought. Although crystal structures depict the conformational average of the molecules constituting the crystalline lattice, a crystal structure of tRNA ${ }^{\text {Asp }}$ shown here consists of an unmodified tRNA molecule exhibiting two slightly different conformations within the asymmetric unit. This finding helps not only to further refine our understanding of the general structural properties of tRNAs obtained primarily through crystallographic data, but also to reconcile these static snapshots with solution-based and computational data that have offered more dynamic views of tRNA behavior (Giegé and Frugier 2000-2013; Fulle and Gohlke 2008; Zhang et al. 2014; Sutton and Pollack 2015; Bao et al. 2017). In addition, we determined the crystal structure of an RNA hairpin construct mimicking the tRNA ${ }^{\text {Asp }}$ acceptor stem stacked onto the TYC stem-loop (tRNA ${ }^{\text {Asp }}$-AS/TSL), which revealed that the TYC loop assumes a tertiary conformation resembling a canonical T-loop, albeit not as well ordered as in tRNA and missing some key interactions that are normally present in tRNAs.

\section{RESULTS}

\section{Model refinement against crystallographic data}

Since we were able to obtain relatively large crystals of $E$. coli tRNA ${ }^{\text {Asp }}$, with the largest crystals exceeding $1 \mathrm{~mm}$ in the longest dimension, we merged several $\mathrm{X}$-ray diffraction data sweeps collected from a single crystal to push the resolution limit of the data. In addition, as there was clear diffraction anisotropy, a data set was processed using the Staraniso server (Tickle et al. 2018) to produce an anisotropic data set. As the crystals are twinned and show anisotropic diffraction, care was taken not to over-interpret the data and to be cautious in the interpretation. We performed paired refinement calculations with increasingly small incremental changes in resolution near $2 \AA$ (approx- imately where we expected the limit to be based on outer shell $1 / \sigma$ and $C_{1 / 2}$ values) to determine objectively the best resolution limit of the data to use in the refinement. By applying paired refinement analysis of $R_{\text {work }}$ and $R_{\text {free }}$ to these data (Karplus and Diederichs 2012), we found that there were meaningful data to as far as $1.99 \AA$ in the isotropic data set that would otherwise be processed to $2.3 \AA$ by previous conventional standards based on $R_{\text {merge }}$ or $R_{\text {measure. }}$ A similar analysis showed that the anisotropic resolution limit was $1.95 \AA$ in the best direction $\left(C_{1 / 2}=0.488\right.$ in the outermost resolution shell). Consistently, model refinement against the isotropic 1.99 $\AA$ data set $\left(C_{1 / 2}=0.404\right.$ in the outermost resolution shell) versus a previous $2.4 \AA$ data set demonstrated clear improvements in the $2 \mathrm{~F}_{\mathrm{o}}-\mathrm{F}_{\mathrm{c}}$ electron density map and in the $R_{\text {free }}$ value of the refined model.

The crystals of the stacked acceptor stem and TYC stemloop had different c-axis lengths depending on the age of the crystals; older crystals had a significantly longer c-axis (281.8 Å vs. $259.3 \AA$ A) and a better ordered T-loop. Older crystals appear to have become dehydrated, but contrary to what is usually observed, the cell axes did not shrink due to dehydration. The apparent reason for the growth of the c-axis is ordering of the loop in the hairpin. In the crystals, the stems align almost parallel to the c-axis and six symmetry related loops face each other at the origin, where threefold and twofold axes intersect. In the long cell crystals, twofold symmetry related bases of C15 in the loop stack on each other as part of the lattice contacts. In the short cell crystals, the loops are disordered as they would interdigitate due to the crystal symmetry. This suggests that growing of the c-axis over time is due to the formation of more stable lattice contacts that allow the loops to separate and form a stable stacking interaction. Thus, in this case, better packing results in cell axis growth. In addition, crystal of both c-axis lengths showed anisotropic diffraction and were processed using the Staraniso server (Tickle et al. 2018) where the cut-off for the mean $(I) / \sigma(I)$ of the accepted data was determined by a similar procedure as for paired refinement. Overall, for both the tRNA ${ }^{\text {Asp }}$ and acceptor stem/TYC stem-loop crystals, extending the resolution limit of the included data resulted in better maps and models, consistent with what has been reported earlier for other RNA crystals (Wang 2010).

\section{Structural differences between the two molecules of $E$. coli tRNA ${ }^{\text {Asp }}$ constituting the crystallographic asymmetric unit}

The overall tertiary structures of the two molecules comprising the crystallographic asymmetric unit of the unmodified E. coli tRNA Asp crystal exhibit the characteristic Lshaped structure of tRNA molecules, which consists of two helical stacks, corresponding to the acceptor stem/ TYC stem-loop and the anticodon/D stem-loop, oriented 
A

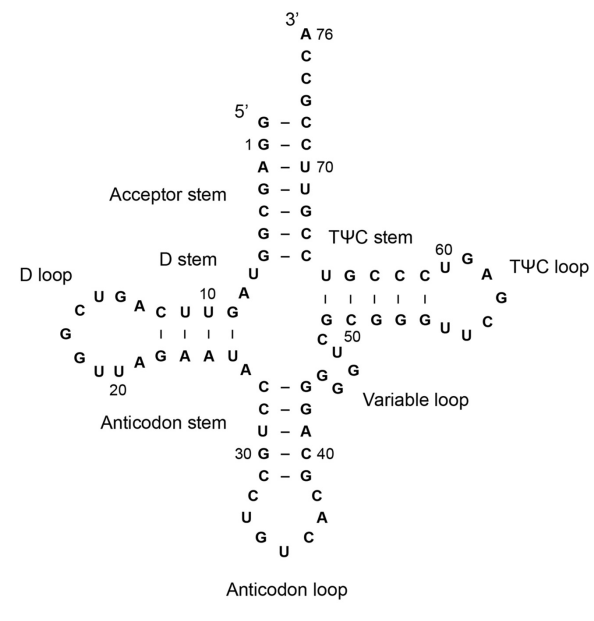

E. coli tRNA ${ }^{\text {Asp }}$
B

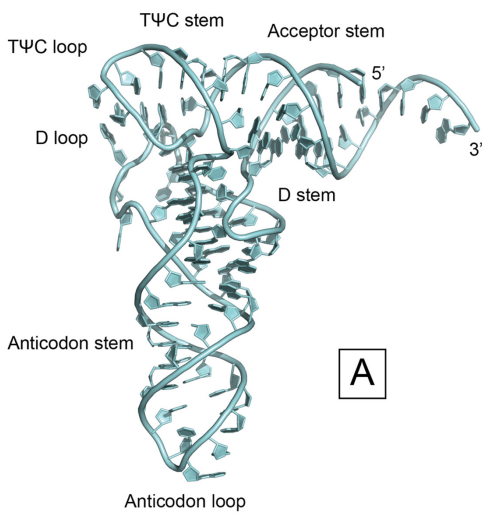

C

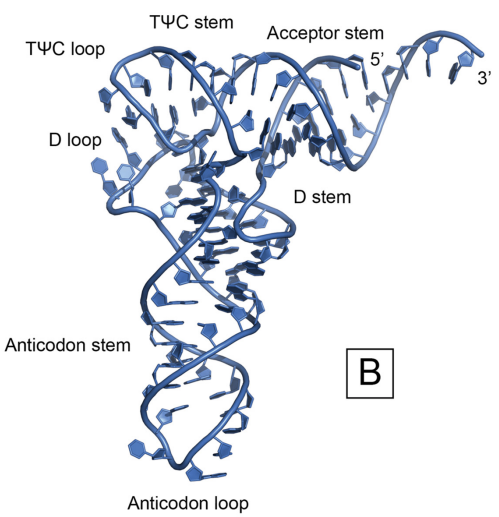

D

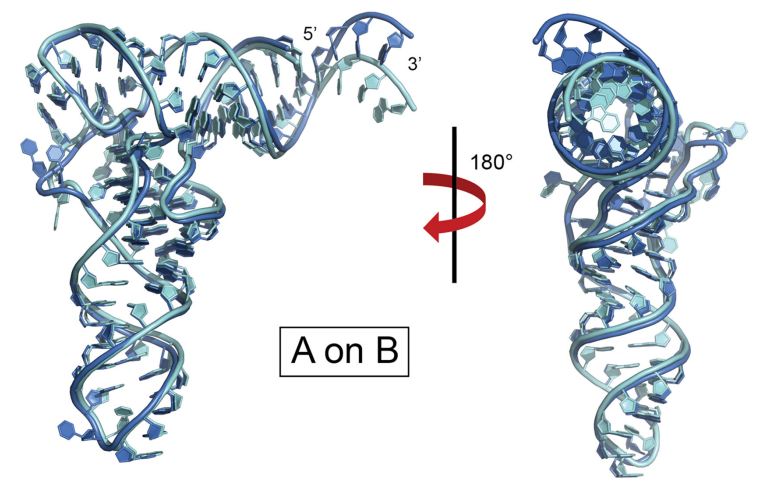

FIGURE 1. Secondary and overall tertiary structure of E. coli tRNA Asp. (A) Secondary structure diagram of E. coli tRNA ${ }^{\text {Asp }}$. (B,C) Overall tertiary structure of the two molecules of E. coli tRNA ${ }^{\text {Asp }}$ (denoted as A,B) that comprise the crystallographic asymmetric unit. (D) Juxtaposition of the two structures reveal several conformational differences between the two models.

near-perpendicularly to each other (Fig. 1). The electron density corresponding to nearly every residue in both molecules was surprisingly well-ordered, which allowed us to build complete models for both tRNAs. Nevertheless, a comparison between the two structures in the asymmetric unit of $E$. coli tRNA ${ }^{\text {Asp }}$ reveals that there are both local and global conformational differences between them.

Superposition of the two non-crystallographic symmetry-related molecules of $E$. coli tRNA Asp (referred to as tRNA $^{\text {Asp }} A$ and $B$ hereafter) demonstrates that there are clear structural differences between the nucleotides at the $3^{\prime}$ end (Fig. 1B,C), the anticodon loops (Fig. 2A,B), the $\mathrm{D}$ loops (Fig. 2C,D), and the angle of their "elbow" region (Fig. 3). Superposition of the two complete structures show a root mean square deviation (rmsd) of $2.52 \AA$ for all atoms, but the rmsd goes down to $1.84 \AA$ when the last four nucleotides are excluded. If the bases are excluded in the latter comparison, the rmsd is $1.53 \AA$, emphasizing that most nucleobases have almost identical conformation, but that globally the differences are significant, likely reflecting a change in overall structure (see below). In addition, analysis of the contacts mediating the crystal packing shows that although there are significant differences between the two monomers in some regions, in general, the packing contacts do not promote these changes.
Supplemental Figure S1 illustrates some of the contacts involving the regions mentioned above.

A previous analysis of the tRNA anticodon loop revealed that several of its defining structural features involve a conserved uridine at position 33; specifically, it was proposed that the atomic interactions between the ribose moiety of U33 and the nucleobase (purine or pyrimidine) of residue 35 and between the uracil moiety of U33 and the backbone phosphates of residues 35 and 36 help to establish the characteristic anticodon loop structure (Auffinger and Westhof 2001). The sugar-phosphate backbone conformations of the anticodon loops of both tRNA ${ }^{\text {Asp }} A$ and $B$ are indeed very similar; however, whereas $U 33_{A}$ is oriented in the canonical position, the nucleobase of $U 33_{B}$ is flipped out from the anticodon loop and faces the $D$ loop of a symmetry-related tRNA ${ }^{\text {Asp }}$ A molecule (Fig. 2A,B). In the crystal structure, $\mathrm{G} 34_{A}-\mathrm{U} 35_{A}-\mathrm{C} 36_{A}$ face $\mathrm{C} 36_{B}-U 35_{B}-$ G34 $4_{B}$ from a non-crystallographic related molecule, with $\mathrm{G} 34_{A}-\mathrm{C} 36_{B}$ and $\mathrm{C} 36_{A}-\mathrm{G} 34_{B}$ forming base pairs, and U35 ${ }_{A}-U 36_{B}$ facing each other, but too far apart to form hydrogen bonds. More importantly, this juxtaposition suggests that despite the conservation of U33 and its key role in the anticodon loop, the canonical position of U33 appears not to be essential for maintaining the backbone conformation of the anticodon loop. In the case of tRNA ${ }^{\text {Asp }}$ 
A

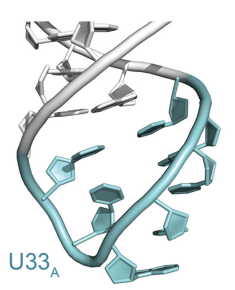

Anticodon loop A

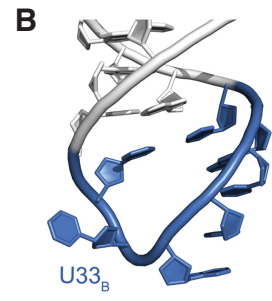

Anticodon loop B
C

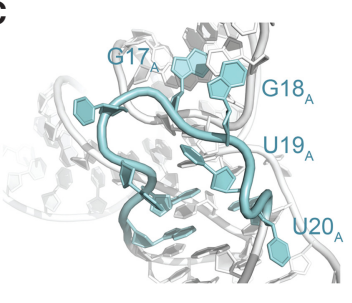

D loop A
D

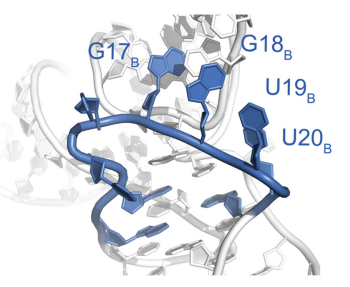

D loop B

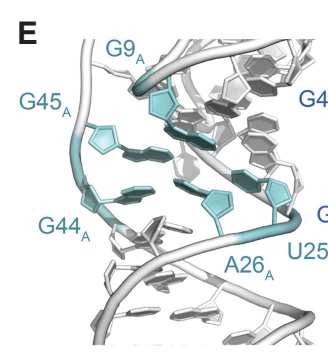

Unmodified E. coli tRNA ${ }^{\text {Asp }} \mathrm{A}$

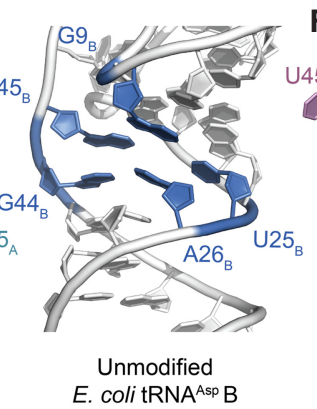

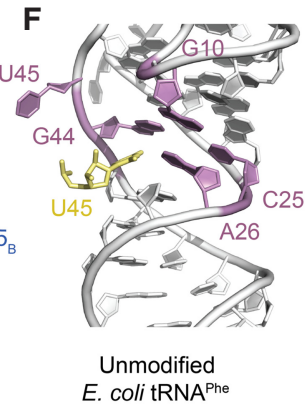

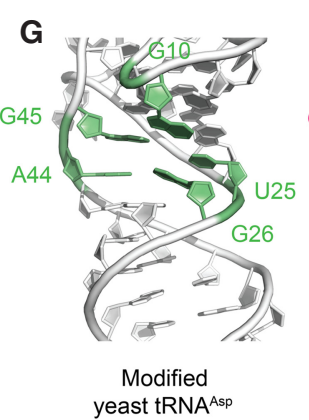

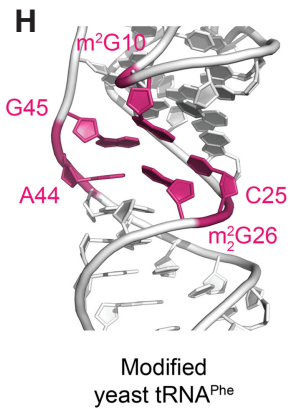

FIGURE 2. Comparative structural analyses between the crystal structure of $E$. coli tRNA ${ }^{A s p}$ with other free tRNA molecules. $(A, B)$ Conformational differences in the anticodon loop of the two molecules of E. colitRNA ${ }^{\text {Asp }}$ that comprise the crystallographic asymmetric unit. $(C, D)$ Conformational differences in the D loop of the two molecules of $E$. coli tRNA ${ }^{\text {Asp }}$ that comprise the crystallographic asymmetric unit. $(E-H)$ The core region of the two molecules of unmodified $E$. coli tRNA ${ }^{A s p}$ that comprise the crystallographic asymmetric unit is very similar in conformation to the core region

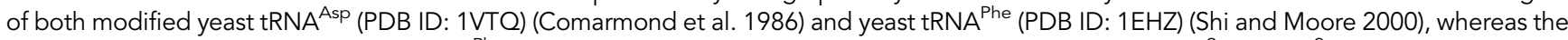
core region of an unmodified E. coli tRNA ${ }^{\text {Phe }}$ (PDB ID: 3LOU) (Byrne et al. 2010) is comparatively different ( $\mathrm{m}^{2} \mathrm{G}$ and $\mathrm{m}_{2}^{2} \mathrm{G}$ represent 2 -methylguanosine and $\mathrm{N}^{2}, \mathrm{~N}^{2}$-dimethylguanosine, respectively). In the latter structure, the extruded U45 forms a crystal lattice contact and is replaced by $\cup 45$ from a symmetry related molecule (yellow).

$B$, the surrounding context of $\mathrm{U} 33_{B}$ has allowed for this particular residue to swivel out toward the solvent space without having any marked structural effect on the rest of the anticodon loop except for the creation of a void in the loop. In both cases, the region surrounding U33 is mainly solvent, thereby providing no apparent reason for the swiveling out of the nucleobase, although there is a minor interaction between $\mathrm{U} 33_{\mathrm{B}}$ and a neighboring molecule.

A comparison of the $D$ loops in tRNA Asp $A$ and $B$ reveals that there is significant conformational variation in this backbone region across the two molecules (Fig. 2C,D), consistent with a previous observation that the $\mathrm{D}$ loop exhibits relatively greater flexibility than other tRNA regions (Byrne et al. 2010). For example, $U 19_{A}$ and $U 20_{A}$ assume markedly different tertiary positions than $\mathrm{U} 19_{B}$ and $\mathrm{U}_{2} \mathrm{O}_{\mathrm{B}}$. In both tRNA ${ }^{\text {Asp }} A$ and $B$, two consecutive and conserved guanidine residues, G17 and G18 (Juhling et al. 2009), insert into the TYC T-loop structure as an intercalated base (Chan et al. 2013) and a hydrogen-bonded pair with the apex (C56) residue of the T-loop, respectively. Thus, G17
A
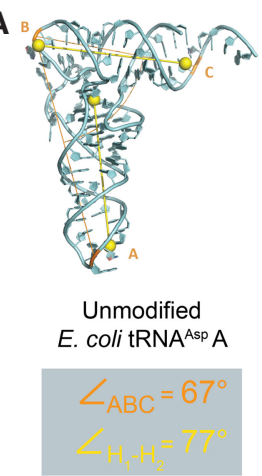

B
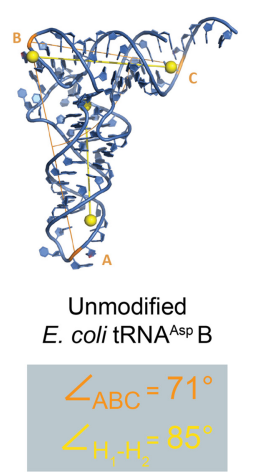

C

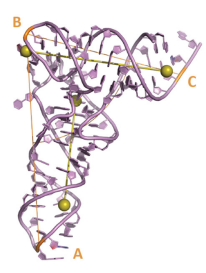

Unmodified E. coli tRNA Phe
D

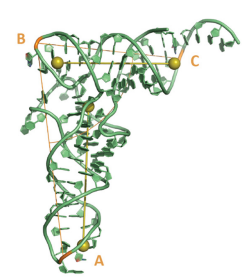

Modified yeast tRNA ${ }^{\text {Asp }}$

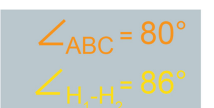

E

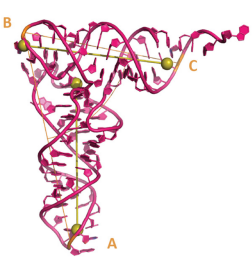

Modified yeast tRNA ${ }^{\text {Phe }}$
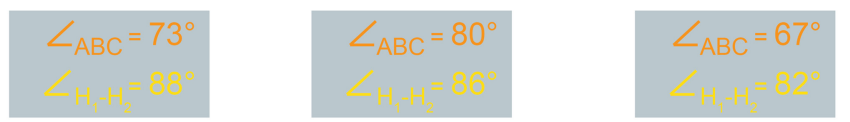

FIGURE 3. Variation in angle of the "elbow" region of tRNAs. The angle of the "elbow" region (made up of the TYC and D loops) varies from tRNA to tRNA without any obvious correlation to the nucleobase modification status of the entire tRNA molecule, as was previously proposed (Byrne et al. 2010). The figure shows the "elbow" angles calculated from three reference points (ABC) and from the angle formed by the best axes of the two stems ( $\mathrm{H} 1-\mathrm{H} 2$; see Materials and Methods). 
and G18 act to dock the proximal region of an otherwise flexible D loop into the TYC loop and may help stabilize the T-loop. Despite the apparent importance of these docking interactions mediated by both $\mathrm{G} 17$ and $\mathrm{G} 18$, the crystal structure of a modified yeast tRNA ${ }^{\text {Asp }}$ (PDB ID: 1VTQ) (Comarmond et al. 1986) reveals a D loop conformation in which $\mathrm{G} 18$ does not engage the TYC loop. In a scenario in which both D loop $\mathrm{G} 17$ and $\mathrm{G} 18$ residues are undocked from the TYC loop, the flexible D loop would be completely solvent accessible and thus primed to be peeled away from the tRNA core. Of note, a large conformational change has been observed in an archaeal tRNA $^{\mathrm{Val}}$ when bound by the archaeosine tRNA-guanine transglycosylase; this alternate but distinct tRNA conformation was termed the $\lambda$-form structure and has a key feature of a disrupted D loop (Ishitani et al. 2003). However, intrinsic flexibility and structural variability of the D loop offer the possibility that the $\lambda$-form structure likely falls within a spectrum of conformations sampled independently by tRNAs and, in this particular case, the role of protein binding is to stabilize rather than to induce this specific conformation.

Given the overall L-shaped tertiary structure of canonical tRNAs, an important measure of global conformation is the angle of their "elbow" region, which is the interhelical angle between the coaxial stacks forming the acceptor stem/TYC stem-loop and the anticodon/D stemloop. By measuring this "elbow" angle using the phosphorus positions of three residues (A35, C56, and C72 or their equivalent nucleotides) in unmodified $E$. coli tRNA $^{\text {Phe }}$, and the angle in several other tRNA structures that are both unbound or bound to protein, it has been proposed previously that nucleotide sequence, modification status, as well as protein binding, all affect the global conformation of tRNA (Byrne et al. 2010). Since the crystal of $E$. coli tRNA ${ }^{\text {Asp }}$ consists of two non-crystallographicsymmetry related molecules, a comparison of the "elbow" angle of the two non-crystallographic-symmetry related molecules of tRNA ${ }^{\text {Asp }}$ provides a direct assessment of the intrinsic flexibility of this tRNA in the absence of protein binding, when the nucleotide sequences are identical, and when there are no nucleotide modifications. In comparison to unmodified E. coli tRNA ${ }^{\text {Phe }}$, which exhibits an "elbow" angle of $73^{\circ}$, tRNA ${ }^{\text {Asp }} A$ and $B$ exhibit more acute "elbow" angles of $67^{\circ}$ and $71^{\circ}$, respectively, (Fig. 3). The difference between the angles measured for tRNA ${ }^{A s p} A$ and $B$ alone suggests that there is an intrinsic flexibility in the unmodified E. coli tRNA ${ }^{\text {Asp }}$ tertiary structure. In this particular instance, the clear difference in global conformation of the tRNAs is likely a mere effect of their surrounding crystalline environment, which may cause the tRNAs to distort in different regions to allow for crystal packing. Of note, a model of yeast tRNA ${ }^{\text {Phe }}$ based on SAXS data reveals a significantly more obtuse "elbow" angle than is present in its crystal structure
(Hammond et al. 2009). Furthermore, comparison of the solution structure of a viral tRNA mimic (Hammond et al. 2009) and its crystal structure (Colussi et al. 2014), which shows a more conventional tRNA-like "elbow" angle, also reveals a significant degree of flexibility in the "elbow" region between the solution and crystal structures that is in turn modulated by an upstream structural element (Hammond et al. 2010).

\section{Comparative structural analysis of representative free tRNA crystal structures}

Despite a previous suggestion that RNA nucleotide sequence differences and nucleobase modifications exert global conformational changes in the overall structure of tRNA (Byrne et al. 2010; Lorenz et al. 2017), we found that crystal packing and crystal-to-crystal variation can account for many of the structural differences observed in the currently available crystal structures of free tRNAs (Figs. 1-3). For instance, in the crystal structure of an unmodified E. coli tRNA ${ }^{\text {Phe }}$ (Byrne et al. 2010), U45 is rotated out from the tRNA core toward solvent space, where it is inserted into the core region of a symmetry-related molecule. In canonical tRNA, U45 would be expected to form a base triple with $\mathrm{G} 10$ and $\mathrm{C} 25$, but the extrusion of U45 precludes the formation of this triple. Instead, a small rearrangement of the backbone brings G44 to the expected location of U45, creating a void in the canonical position of G44 and preventing the formation of the expected A26-G44 base pair. The space left open by the movement of G44 to form the triple is taken over by U45 of a symmetry related molecule, creating an $U 45^{\text {sym }}$ A 26 base pair. Thus, the core structure is rearranged relative to that of the prototypic tRNA core (Fig. 2 ), but the overall structure remains fairly similar due to the rearrangements and the movement of a symmetry related nucleotide.

The general structure of the tRNA core appears to be conserved across different tRNA molecules, irrespective of nucleobase modifications and, to some degree, sequence variation (Fig. 2E-H). A comparison of the cores of unmodified $E$. coli tRNA $^{\text {Phe }}$ and modified yeast tRNA ${ }^{\text {Phe }}$ shows close similarity between their central base triple, G10-C25-G44/G10-C25-G45 (even though in the latter molecule $\mathrm{G} 10$ is $\mathrm{N}_{2}$-methylated) and between the adjacent base pair (U45 $5^{\mathrm{sym}}-\mathrm{A} 26$ and A44.G26 in the unmodified and modified molecules, respectively, where $\mathrm{G} 26$ is $\mathrm{N}_{2}$-dimethylated in the latter case). The U45 $5^{\text {sym }}$ A26 pair does not form a canonical base pair as the symmetry related molecule forms a highly buckled pair with only $N_{1}$ of $A 26$ and $N_{3}$ of $U 45$ within hydrogen bonding distance, whereas $\mathrm{N}_{6}$ of $\mathrm{A} 26$ and $\mathrm{O}_{4}$ of $\mathrm{U} 45$ are too far apart due to the absence of coplanarity. Furthermore, a comparison of the cores of the unmodified E. coli tRNA ${ }^{A s p}$ and the modified yeast tRNA ${ }^{\text {Asp }}$ reveals 
that this adjacent base pair in the two molecules are interchangeably $G \cdot A$ or $A \cdot G$, respectively. Finally, a comparison between modified tRNA ${ }^{\text {Asp }}$ and modified tRNA ${ }^{\text {Phe }}$ shows that either $U$ or $C$ can occur at position 25 , as long as the base triple configuration is maintained. These comparisons reveal that despite the general importance ascribed to specific residues or modifications in tRNA function and metabolism, there exists a clear degree of plasticity in the canonical structure of the tRNA core that acts to buffer against the tertiary level effects of sequence variation and nucleobase modifications.

By measuring the "elbow" angle of the modified yeast tRNA structures and comparing them with the angles measured for their unmodified E. coli counterparts, we found that there was no obvious correlation between the measured angles and whether a tRNA molecule is modified or unmodified. This observation suggests that nucleobase modifications do not result in a global change in tRNA structure, at least to an extent that is discernable by changes in the "elbow" angle. In fact, we found that there were greater differences in the measured "elbow" angles simply due to how the angles were measured (i.e., by using three reference phosphorus atoms in the acceptor stem, the TYC loop, and the anticodon loop [Byrne et al. 2010], or by defining coaxial vectors for the acceptor stem/TYC stem-loop and the anticodon/D stem-loop stacks) than there were within each set of measurements (Fig. 3); however, we also note that some of the discrepancy between the two methods is that they do not equally reflect twisting at the "elbow." Taken together, we propose an alternative explanation for the observed variation in the "elbow" angles of these tRNA structures: tRNAs are intrinsically flexible molecules whose "elbow" region can conform to both bending and twisting imposed by crystallization.

\section{Crystal structure of a fragment of $E$. coli tRNA ${ }^{\text {Asp }}$ consisting of its acceptor stem/TYC stem-loop}

As a part of this study, we crystallized an RNA hairpin molecule equivalent to the $E$. coli tRNA Asp TYC stem-loop stacked on its acceptor stem (Fig. 4). In the absence of its native tertiary context, the TYC loop assumed a conformation that resembles a T-loop (Fig. 5), although the nucleotides forming the loop are not as well ordered as in tRNA. RNA structural motifs are frequently catalogued with an underlying assumption that there exists a sequence consensus for each motif and that they all share the same structure (Fernández-Millán et al. 2016). As noted previously (Chan et al. 2013), the T-loop motif does not appear to have as strong a sequence consensus as other motifs and, unlike many other motifs, T-loops can only be identified confidently based on tertiary structure. It is thus surprising that the T-loop is formed in the absence of important stabilizing interactions, such as the ones with the D-loop nucleotides. This suggests that the propensity to form a T-loop is in fact encoded in the $E$. coli tRNA ${ }^{\text {Asp }}$ TYC loop sequence and that T-loop formation can occur even in the absence of the D-loop, which is consistent with the modified tRNA ${ }^{\text {Asp }}$ structure (Comarmond et al. 1986), which shows a T-loop even though some of the interactions are not present.
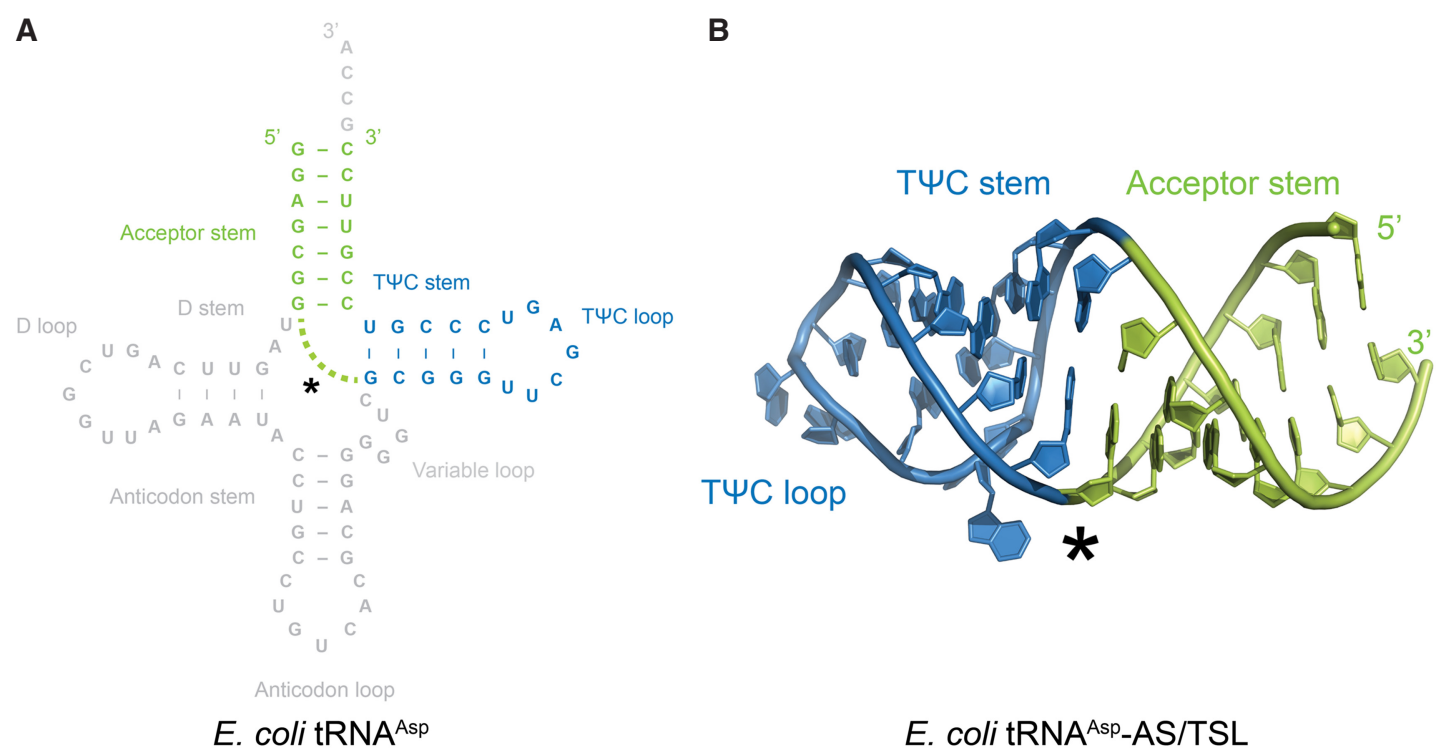

FIGURE 4. Secondary and overall tertiary structure of E. colitRNA Asp_AS/TSL. (A) Secondary structure diagram of the crystallized RNA stem-loop construct, which consists of the acceptor stem (AS, colored in green) and the TYC stem-loop (TSL, colored in blue) of E. coli tRNA ${ }^{\text {Asp }}$. (B) Overall tertiary structure of the E. coli tRNA ${ }^{\text {Asp }}$-AS/TSL (with coloring as in A), in which the TYC loop exhibits a T-loop conformation. The asterisk shows the region where the TYC stem and acceptor stems were linked to bypass the anticodon and D stems. 


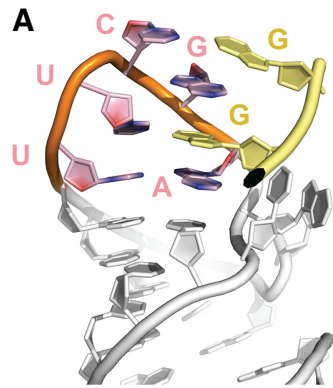

tRNA ${ }^{A s p}$ T $\Psi \mathrm{C}$ 5'-UUCGA-3' T-loop conformation
B

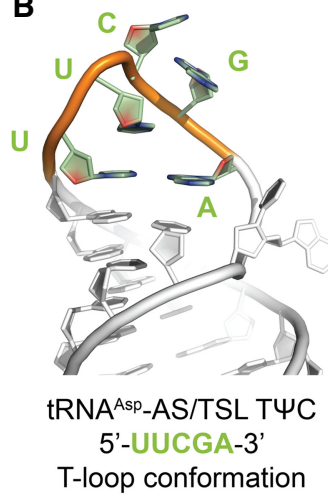

C

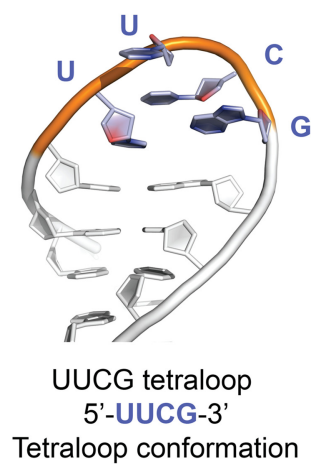

FIGURE 5. Residues comprising the E. coli tRNA Asp T $\Psi C$ loop exhibit a T-loop structural fold in a context-independent manner. (A) TYC loop in the crystal structure of full-length $E$. coli tRNA ${ }^{\text {Asp }}$ assumes the canonical T-loop conformation while engaging in tertiary interactions with $D$ loop residues (yellow) acting as intercalating and stacked nucleobases. (B) TYC loop in the crystal structure of $E$. coli tRNA ${ }^{\text {Asp }}$-AS/TSL reveals a T-loop conformation, despite the absence of the D loop interactions, and not a UUCG tetraloop conformation (illustrated in C), as could be expected from sequence analysis.

\section{DISCUSSION}

The crystal structure of $E$. coli tRNA ${ }^{\text {Asp }}$ demonstrates that structural flexibility is an intrinsic property of tRNAs. In the absence of external modifying factors, such as binding by proteins or other RNAs, the surrounding crystalline conditions are sufficient to generate conformational changes that in previous structures were attributed to the action of proteins or other factors, such as nucleotide sequence differences and nucleobase modifications. This is further illustrated in Supplemental Figure S2, which shows superpositions of both $E$. coli tRNA Asp molecules with other tRNAs found in complex with proteins, other RNAs, or the ribosome. The comparisons demonstrate that, in general, the structural variability found between both $E$. coli tRNA ${ }^{\text {Asp }}$ molecules is within the range of changes induced by tRNA binding to another macromolecule. Similarly, prior suggestion that RNA nucleobase modifications exert a global effect on an entire RNA molecule were based on the observation that an unmodified tRNA molecule exhibits a different structural conformation than their modified counterparts (Byrne et al. 2010). Between the two molecules of $E$. coli tRNA ${ }^{\text {Asp }}$ that comprise its crystallographic asymmetric unit, we found a similar degree of structural variation attributed previously to the absence versus presence of nucleobase modifications, thereby suggesting that it is rather the flexible nature of tRNAs that is being exemplified by these crystal structures.

We also demonstrated that the E. coli tRNA Asp TUC loop can form even in the absence of all stabilizing interactions. Since the E. colitRNA Asp TYC loop consists of a sequence that fits the consensus of both a T-loop and a UUCG tetraloop, it could be assumed that the loop has an intrinsic propensity to assume either structural conformation. In the context of a full-length tRNA molecule, the 5'-UUCGA-3' segment of the TYC loop forms a T-loop motif with an intercalated nucleobase (G17) supplied by the D loop. In the absence of this tertiary interaction, the isolated TYC loop still forms a loop that is closer in structure to a Tloop than to a UUCG tetraloop, although the apex of the loop is partially disordered. This is direct evidence showing that there is a hierarchy in structure formation when two distinct motifs can be formed in a single RNA sequence. In this case, the Tloop seems to take precedence over the tetraloop, even though not all the expected interactions are present.

Given that there are far fewer available crystal structures of RNAs than of proteins, it is interesting to note which RNA-RNA interactions mediate crystal lattice contacts in new RNA structures. In the crystal of $E$. coli tRNA ${ }^{\text {Asp }}$, which contains two non-crystallographic symmetry-related molecules, there are surprisingly few crystal lattice contacts. Furthermore, these intermolecular RNA-RNA interactions consist primarily of coaxial stacking, base pairing, and base stacking (Supplemental Fig. S3), which are also the primary and familiar mediators of intramolecular interactions in folded RNA molecules. This observation supports the notion that folded RNA molecules utilize the same RNA-RNA interactions for both intramolecular stabilization and assembly on the quaternary level.

Finally, an evolutionary implication of tRNA structural flexibility is that it helps to reduce selective pressures on both natural tRNA structural mimics and tRNA modifiers since the structures that they adopt or need to act on, respectively, do not necessarily need to assume a very specific and rigid conformation. This is not to say that tRNA tertiary structures are not significantly affected by nucleotide sequence or modification, but merely that their intrinsic flexibility alone allows for greater functional versatility. From a general functional perspective, inherent flexibility of tRNAs (and, by extension, folded RNA molecules) also suggests that they are perhaps more active participants in biological processes than previously thought, particularly since the current paradigm for RNA-based biological processes is that non-coding RNA molecules are passive and rigid structural entities that function primarily by being acted upon by proteins or other RNA-protein complexes.

In conclusion, our crystallographic studies of $E$. coli tRNA ${ }^{\text {Asp }}$ provide further evidence that structural flexibility is an intrinsic property of tRNAs and of folded RNA molecules in general. In a broader context, this finding challenges a widespread view that folded tRNA molecules 
are structurally static unless chemically modified or physically acted upon. Furthermore, we also provide data demonstrating that there is structural hierarchy underlying RNA structural motifs, the basic structural units of folded RNA, such that a complete bottom-up approach to understanding RNA folding must take into account that sequences conforming to more than one structural motif may prefer one over the other in a manner that may not be easy to predict.

\section{MATERIALS AND METHODS}

\section{Transcription and RNA purification}

Full-length Escherichia coli tRNA ${ }^{\text {Asp }}$ and a truncated RNA hairpin

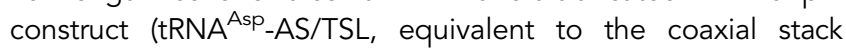
formed by the acceptor stem/TYC stem-loop) were produced in vitro on the milligram scale by run-off transcription using recombinant T7 RNA polymerase and standard reaction conditions (Milligan et al. 1987). In brief, the DNA template encoding E. coli tRNA ${ }^{\text {Asp }}$ for transcription was cloned into the multiple cloning site of pUC19 with an upstream T7 RNA polymerase promoter element and a BsmAl restriction site immediately $3^{\prime}$ to the coding region. This plasmid was transformed into and thus replicated in a culture of E. coli $\mathrm{DH} 5 \alpha$ grown in Terrific Broth media and purified by conventional alkaline lysis methods, followed by phenolchloroform extraction and selective PEG 6000 precipitation, to remove contaminating cellular host proteins and RNAs, respectively. The purified plasmid DNA was subsequently digested with BsmAl (New England BioLabs) and purified further by phenol-chloroform extraction and ethanol precipitation. In contrast, the DNA template encoding E. coli tRNA ${ }^{\text {Asp }}$-AS/TSL for transcription was generated by annealing complementary oligonucleotides purchased from Integrated DNA Technologies. The sequences of the two oligonucleotides are as follows: $5^{\prime}$ CGACGTAATACGACTCACTATAGGAGCGGGCGGGTTCGAGT CCCGTCCGTTCC-3' and 5'-GGAACGGACGGGACTCGAACCC GCCCGCTCCTATAGTGAGTCGTATTACGTCG-3'; the annealed product contains the T7 RNA polymerase promoter element upstream of the coding region. For annealing, the two oligonucleotides were incubated for $2 \mathrm{~min}$ at $90^{\circ} \mathrm{C}$ at an equal molar stoichiometric ratio, cooled subsequently to room temperature on a benchtop, and used directly for in vitro transcription.

Following in vitro transcription, E. coli tRNA ${ }^{\text {Asp }}$ and tRNA ${ }^{\text {Asp }}$ AS/TSL were separated from short transcripts and other reaction components by electrophoresis in a native $10 \%$ acrylamide gel ran in $89 \mathrm{mM}$ Tris- $\mathrm{HCl}, \mathrm{pH} 7.6,89 \mathrm{mM}$ boric acid (1× TB buffer). The principal gel band corresponding to each transcription product was located by UV shadowing and extracted into $50 \mathrm{mM}$ potassium acetate, $\mathrm{pH} 7.0,200 \mathrm{mM}$ potassium chloride by passive diffusion at $4^{\circ} \mathrm{C}$. The extracted RNAs were both precipitated with ethanol and stored at $-20^{\circ} \mathrm{C}$.

The gel-purified and precipitated E. coli tRNA ${ }^{\text {Asp }}$ (Supplemental Fig. S4A) was resuspended in $50 \mathrm{mM}$ Tris- $\mathrm{HCl}$, $\mathrm{pH}$ 7.5, $200 \mathrm{mM}$ sodium chloride, $5 \mathrm{mM}$ magnesium chloride and further purified by size exclusion chromatography on an FPLC instrument (ÄKTA, GE Healthcare) using a Superdex 200 10/300 GL column ran with $50 \mathrm{mM}$ Tris- $\mathrm{HCl}, \mathrm{pH} 7.5,200 \mathrm{mM}$ sodium chloride, $5 \mathrm{mM}$ magnesium chloride (Supplemental Fig. S4B). The FPLC-purified E. coli tRNA ${ }^{A s p}$ was then both buffered-exchanged into $50 \mathrm{mM}$ Tris- $\mathrm{HCl}, \mathrm{pH} 7.5,200 \mathrm{mM}$ sodium chloride, $40 \mathrm{mM}$ potassium chloride, $10 \mathrm{mM}$ magnesium chloride and concentrated using $10 \mathrm{kDa}$ MWCO spin concentrators containing either a cellulose acetate (Millipore) or polyethersulfone (GE Healthcare) membrane to a final concentration of $\sim 20$ $\mathrm{mg} / \mathrm{mL}$. In contrast, the gel-purified and precipitated $E$. coli tRNA ${ }^{\text {Asp }}$-AS/TSL was resuspended in $50 \mathrm{mM}$ Tris- $\mathrm{HCl}, \mathrm{pH} 7.5$, $200 \mathrm{mM}$ sodium chloride, $5 \mathrm{mM}$ magnesium chloride, filtered using a $0.22 \mu \mathrm{m}$ spin column with a cellulose acetate membrane, and used directly for crystallization trials. The concentration of E. coli tRNA Asp_AS/TSL used for crystallization ranged between 1 to $4 \mathrm{mg} / \mathrm{mL}$.

\section{Crystallization and structure determination of $E$. coli tRNA ${ }^{\text {Asp }}$}

Crystals of $E$. coli tRNA ${ }^{\text {Asp }}$ were grown at $287 \mathrm{~K}$ by vapor diffusion in a hanging drop format over a range of equilibration solutions optimized around $50 \mathrm{mM}$ sodium cacodylate, $\mathrm{pH} 7.0,30 \%$ v/v 2-methyl-2,4-pentanediol (MPD). Although we found that the presence of various salts (up to $300 \mathrm{mM}$ sodium chloride and 300 $\mathrm{mM}$ potassium chloride) and polyamines (1 to $10 \mathrm{mM}$ spermine or spermine tetrahydrochloride), the coverslip material (siliconized glass, unsiliconized glass, and plastic coverslips), and different sample concentrations (ranging from 5 to $20 \mathrm{mg} / \mathrm{mL}$ of E. coli tRNA ${ }^{\text {Asp }}$ ) all had varying effects on the morphology of the crystals, which often grew in large clusters (Supplemental Fig. S4C), there was no obvious correlation between these factors and the eventual size or diffraction limit of the crystals. However, since the crystals tended to grow in clusters, manual manipulation was often needed to excise fragments suitable for data collection. Our best diffracting, and also the largest, single crystal of E. coli tRNA Asp (Supplemental Fig. S4C) was grown from a mixture of $2 \mu \mathrm{L}$ of $20 \mathrm{mg} / \mathrm{mL}$ E. coli tRNA ${ }^{\text {Asp }}$ and $2 \mu \mathrm{L}$ of $50 \mathrm{mM}$ sodium cacodylate, $\mathrm{pH}$ 7.5, 30\% MPD, $10 \mathrm{mM}$ spermine tetrahydrochloride, $300 \mathrm{mM}$ sodium chloride, $300 \mathrm{mM}$ potassium chloride (equilibration solution), and $0.5 \mu \mathrm{L}$ of Hampton Research Silver Bullet Additive No. 23, which consists of $0.25 \%$ $\mathrm{w} / \mathrm{v} \mathrm{p}$-coumaric acid, $0.25 \% \mathrm{w} / \mathrm{v}$ phenylurea, $0.25 \% \mathrm{w} / \mathrm{v}$ poly(3hydroxybutyric acid), $0.25 \% \mathrm{w} / \mathrm{v}$ sulfaguanidine, $0.02 \mathrm{M}$ sodium HEPES, pH 6.8.

X-ray diffraction data (Supplemental Fig. S4C) were collected at $100 \mathrm{~K}$ at the Life Sciences Collaborative Access Team (LSCAT) beamlines at the Advanced Photon Source (APS), Argonne National Laboratory, using a Dectris Eiger 9M detector. Crystals of $E$. coli tRNA Asp were flash frozen directly in mother liquor with liquid nitrogen for data collection since the MPD content of the mother liquor was sufficient for cryo-protection. Processing of diffraction data was carried out using XDS (Kabsch 2010) for indexing and integration and AIMLESS (Evans and Murshudov 2013) for merging and scaling. The crystal structure of E. coli tRNA ${ }^{\text {Asp }}$ was solved by molecular replacement using a homology model generated by Chainsaw (Stein 2008) in CCP4 (Winn et al. 2011) using the crystal structure of a modified yeast $R N A^{\text {Phe }}$ (PDB ID: 1EHZ) (Shi and Moore 2000) with the primary sequence of $E$. coli tRNA ${ }^{\text {Asp }}$ threaded through. Although the vast majority of $E$. coli tRNA ${ }^{\text {Asp }}$ crystals were twinned, we 
were able to collect a data set from an untwinned crystal, which allowed us to solve its structure and generate an initial model $(R /$ $R_{\text {free }}=0.20 / 0.26$ at $2.85 \AA$ ). Twinned crystals were subsequently used for refinement to high resolution. As the crystals showed anisotropic diffraction, data were re-processed using the Staraniso server (Tickle et al. 2018) to produce the final data set. All iterative rounds of model building and refinement were performed with Coot (Emsley and Cowtan 2004) and Refmac5 (Murshudov et al. 1997). The final models (isotropic to $1.99 \AA$ $R / R_{\text {free }}=0.218 / 0.244$ and anisotropic to $1.95 \AA R / R_{\text {free }}=0.215 /$
0.238) were determined from the highest resolution data set collected. Additional X-ray crystallographic statistics for $E$. coli tRNA $^{\text {Asp }}$ are summarized in Table 1 . The $2 \mathrm{mF}_{\mathrm{O}}-\mathrm{DF}_{\mathrm{C}}$ map, calculated with coefficients output by Refmac (Murshudov et al. 1997), and simulated annealing omit maps calculated with Phenix (Afonine et al. 2012) for two different regions of the crystal are shown in Supplemental Figure S5 to illustrate the quality of the maps. Only the coordinates for the model refined against the anisotropic data were deposited in the PDB as the two sets are virtually identical.

TABLE 1. X-ray crystallographic statistics for crystals of E. coli tRNA Asp

\begin{tabular}{|c|c|c|c|}
\hline Data collection & $\begin{array}{l}\text { Untwinned } \\
\text { (low-resolution) }\end{array}$ & $\begin{array}{l}\text { Twinned high resolution } \\
\text { anisotropic }\end{array}$ & $\begin{array}{c}\text { Twinned high resolution } \\
\text { isotropic }\end{array}$ \\
\hline Detector type/source & Eiger 6M/APS LS-CAT & Eiger 6M/APS LS-CAT & Eiger 6M/APS LS-CAT \\
\hline Wavelength (Å) & 1.2524 & 1.0782 & 1.0782 \\
\hline Space group & $P 3,21$ & $P 3,21$ & $P 3,21$ \\
\hline Cell parameters & $\begin{array}{c}a=b=65.0 \AA \\
c=193.8 \AA\end{array}$ & $\begin{array}{c}a=b=64.7 \AA \\
c=195.8 \AA\end{array}$ & $\begin{array}{c}a=b=64.7 \AA \\
c=195.8 \AA\end{array}$ \\
\hline Number of data sets & 1 & 3 & 3 \\
\hline $\begin{array}{l}\text { Rotation range and total } \\
\text { rotation per pass }\end{array}$ & $0.25^{\circ} / 180^{\circ}$ & $0.25^{\circ} / 180^{\circ}$ & $0.25^{\circ} / 180^{\circ}$ \\
\hline Resolution range $(\AA ̊)^{a}$ & $48.68-2.85$ (3.00-2.85) & 48.62-1.95 (2.056-1.95) & 48.62-1.99 (2.04-1.99) \\
\hline Total number of observations & $222,139(32,320)$ & $945,153(55,102)$ & $1,000,512(72,729)$ \\
\hline Unique reflections & $11,714(1664)$ & $31,542(1637)$ & $33,642(2351)$ \\
\hline Mean $(I) / \sigma(I)$ & $19.1(6.7)$ & $15.8(1.8)$ & $14.9(1.4)$ \\
\hline Completeness (spherical) (\%) & $99.6(99.9)$ & $88.5(31.8)$ & $100.0(100.0)$ \\
\hline Completeness (ellipsoidal) (\%) & - & $94.0(50.8)$ & - \\
\hline Multiplicity & $19.0(19.4)$ & $30.0(33.7)$ & 29.7 (30.9) \\
\hline$R_{\text {merge }}($ all I+ \& I-) & $0.144(0.501)$ & $0.155(2.683)$ & $0.161(3.447)$ \\
\hline$R_{\text {merge }}$ (within $\mathrm{I}+/ \mathrm{I}-$ ) & $0.146(0.512)$ & $0.152(2.632)$ & $0.163(3.502)$ \\
\hline$R_{\text {meas }}($ all I+ \& I-) & $0.152(0.528)$ & $0.158(2.724)$ & $0.167(3.556)$ \\
\hline$R_{\text {meas }}$ (within $I+/ I-$ ) & $0.150(0.526)$ & $0.157(2.712)$ & $0.166(3.560)$ \\
\hline$R_{\text {pim }}($ all I+ \& I-) & $0.047(0.165)$ & $0.029(0.468)$ & $0.042(0.872)$ \\
\hline$R_{\text {pim }}$ (within I+/I-) & $0.034(0.119)$ & $0.039(0.649)$ & $0.031(0.634)$ \\
\hline $\mathrm{CC}(1 / 2)$ & $0.996(0.966)$ & $0.992(0.488)$ & $0.993(0.404)$ \\
\hline \multicolumn{4}{|l|}{ Refinement } \\
\hline $\begin{array}{l}\text { Number of reflections } \\
\text { working/test }\end{array}$ & & $30,070 / 1469(262 / 13)$ & $31,946 / 1605$ (2269/151) \\
\hline$R$ (working set; \%) & & $21.5(28.6)$ & $21.8(26.9)$ \\
\hline$R_{\text {free }}(\%)$ & & $23.8(50.2)$ & $24.4(32.4)$ \\
\hline \multicolumn{4}{|l|}{ Structure quality } \\
\hline RNA atoms & & 3288 & 3288 \\
\hline Other atoms & & 23 & 23 \\
\hline $\begin{array}{l}\text { RMS deviations in bond } \\
\text { lengths }(\AA)\end{array}$ & & 0.003 & 0.003 \\
\hline RMS deviations in bond angles $\left(^{\circ}\right)$ & & 0.850 & 0.845 \\
\hline \multicolumn{4}{|l|}{ Average B factor $\left(\AA^{2}\right)$} \\
\hline Chain A & & 57.2 & 54.7 \\
\hline Chain B & & 51.7 & 50.4 \\
\hline Waters & & 36.7 & 38.9 \\
\hline
\end{tabular}

${ }^{a}$ All numbers in parentheses are for highest resolution shell. 


\section{Crystallization and structure determination of an RNA hairpin consisting of the acceptor stem and TYC stem-loop of $E$. coli tRNA ${ }^{\text {Asp }}$}

Crystals of $E$. coli tRNA ${ }^{\text {Asp }}$-AS/TSL were also grown at $287 \mathrm{~K}$ by vapor diffusion in a hanging drop format over a range of equilibration solutions optimized around $2 \mathrm{M}$ ammonium sulfate (Supplemental Fig. S6A). Crystals of E. coli tRNA Asp-AS/TSL were flash frozen with liquid nitrogen in crystallization well solution supplemented with either increased ammonium sulfate concentration or with $20 \%(\mathrm{v} / \mathrm{v})$ glycerol for cryo-protection. For data collection, X-ray diffraction data (Supplemental Fig. S6B) were collected at $100 \mathrm{~K}$ at LS-CAT at the APS, Argonne National Laboratory, using a Dectris Eiger 9M detector. Processing of diffraction data was carried out using XDS (Kabsch 2010) for indexing and integration and AIMLESS (Evans and Murshudov 2013) for merging and scaling. Final anisotropic data sets were obtained using the Staraniso server (Tickle et al. 2018). The crystal structure of E. coli tRNA ${ }^{\text {Asp }}$ -
AS/TSL was solved by molecular replacement using coordinates for an idealized 5 bp A-form RNA helix (Robertson and Scott 2008) generated in Coot (Emsley and Cowtan 2004). Additional electron density for the rest of the molecule appeared subsequently in iterative rounds of model building and refinement, which were performed with Coot (Emsley and Cowtan 2004) and Refmac5 (Murshudov et al. 1997), respectively. The length of the c-axis was different depending on the age of the crystals such that older crystals had a longer c-axis and a better ordered Tloop, whereas fresher crystals had a shorter c-axis and a disordered T-loop. The final models for E. colitRNA Asp-AS/TSL had an $R / R_{\text {free }}$ $=0.214 / 0.272$ to $1.6 \AA$ resolution and $R / R_{\text {free }}=0.231 / 0.256$ to 1.75 $\AA$ for the short and long axis crystals respectively. Additional $\mathrm{X}$-ray crystallographic statistics are summarized in Table 2. The $2 \mathrm{mF}_{\mathrm{O}^{-}}$ $D_{C}$ map, calculated with coefficients output by Refmac (Murshudov et al. 1997), and simulated annealing omit maps calculated with Phenix (Afonine et al. 2012) are shown in Supplemental Figures S7, S8 to illustrate the quality of the maps.

TABLE 2. X-ray crystallographic statistics for crystals of E. coli tRNA ${ }^{\text {Asp }}$-AS/TSL

\begin{tabular}{|c|c|c|}
\hline Data collection & Long unit cell crystal & Short unit cell crystal \\
\hline Detector type/source & Eiger 6M/APS LS-CAT & Eiger 6M/APS LS-CAT \\
\hline Wavelength $(\AA ̊)$ & 1.272 & 0.9762 \\
\hline Space group & $\mathrm{H} 32$ & H32 \\
\hline Cell parameters & $a=b=43.5 \AA, c=281.8 \AA$ & $a=b=43.9 \AA, c=259.3 \AA$ \\
\hline Number of data sets & 1 & 4 \\
\hline Rotation range and total rotation per pass & $0.2^{\circ} / 160^{\circ}$ & $0.5^{\circ} / 100^{\circ}$ \\
\hline Resolution range $(\AA)^{a}$ & $37.36-1.754(1.872-1.754)$ & $43.214-1.602(1.691-1.602)$ \\
\hline Total number of observations & $74,211(3401)$ & $207,628(6865)$ \\
\hline Unique reflections & $9182(458)$ & 9570 (479) \\
\hline Mean $(I) / \sigma(I)$ & $8.2(1.2)$ & $11.5(1.0)$ \\
\hline Completeness (spherical) (\%) & $84.3(24.3)$ & $72.2(24.7)$ \\
\hline Completeness (ellipsoidal) (\%) & $89.0(34.9)$ & $92.0(68.8)$ \\
\hline Multiplicity & $8.1(7.4)$ & $21.7(14.3)$ \\
\hline$R_{\text {merge }}($ all I+ \& I-) & $0.118(1.257)$ & $0.156(4.054)$ \\
\hline$R_{\text {merge }}$ (within $\mathrm{I}+/ \mathrm{I}-$ ) & $0.116(1.202)$ & $0.159(3.742)$ \\
\hline$R_{\text {meas }}($ all I+ \& I-) & $0.126(1.354)$ & $0.160(4.2)$ \\
\hline$R_{\text {meas }}$ (within I+/I-) & $0.132(1.382)$ & $0.167(4.01)$ \\
\hline$R_{\text {pim }}($ all I+ \& I-) & $0.045(0.494)$ & $0.034(1.089)$ \\
\hline$R_{\text {pim }}$ (within I+/I-) & $0.062(0.673)$ & $0.048(1.422)$ \\
\hline $\mathrm{CC}(1 / 2)$ & $0.997(0.683)$ & $0.999(0.492)$ \\
\hline \multicolumn{3}{|l|}{ Refinement } \\
\hline Number of reflections working/test & $8809 / 200(479 / 5)$ & $9077 / 187(492 / 7)$ \\
\hline$R$ (working set; \%) & $23.1(40.5)$ & $21.4(39.9)$ \\
\hline$R_{\text {free }}(\%)$ & $25.6(19.9)$ & $27.2(29.9)$ \\
\hline \multicolumn{3}{|l|}{ Structure quality } \\
\hline RNA atoms & 664 & 600 \\
\hline Other atoms & 75 & 92 \\
\hline RMS deviations in bond lengths $(\AA)$ & 0.010 & 0.009 \\
\hline RMS deviations in bond angles $\left(^{\circ}\right)$ & 1.913 & 1.615 \\
\hline \multicolumn{3}{|l|}{ Average $B$ factor $\left(\AA^{2}\right)$} \\
\hline Chain A & 35.2 & 37.1 \\
\hline Waters & 35.5 & 37.3 \\
\hline
\end{tabular}

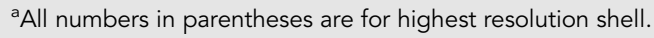


Coordinates for the long and short cell models refined against their respective anisotropic data were deposited in the PDB.

\section{Visualization and comparative analysis of structural models}

The crystal structures of the tRNA molecules were aligned by least squares fitting in Coot (Emsley and Cowtan 2004) using the atomic coordinates of their TYC loop (residues 54 to 58 in E. coli tRNA ${ }^{\text {Asp }}$ ). PyMOL (The PyMOL Molecular Graphics System, Schrödinger, LLC) was used to depict all structural models and to measure the "elbow" angle of the tRNA molecules based on the position of three reference atoms, as done in a previous analysis (Byrne et al. 2010). To calculate an alternate and more representative measure of the inter-helical angle between the acceptor stem/TYC stem and the anticodon/D stem helical stacks of each tRNA molecule, we applied the law of cosines to stem axial vectors determined by the DSSR software (Lu et al. 2015) of the 3DNA program suite (Lu and Olson 2003, 2008a,b).

\section{DATA DEPOSITION}

Atomic coordinates and structure factors for the reported crystal structures have been deposited with the Protein Data Bank under accession numbers 6UGG (E. coli tRNA ${ }^{\text {Asp }}$ model), 6UGI (E. coli tRNA ${ }^{\text {Asp }}$-AS/TSL, long cell model), and 6UGJ (E. coli tRNA ${ }^{\text {Asp }}$ AS/TSL, short cell model).

\section{SUPPLEMENTAL MATERIAL}

Supplemental material is available for this article.

\section{ACKNOWLEDGMENTS}

We thank Lei Huang for providing us with a plasmid encoding the E. colitRNA ${ }^{\text {Asp }}$ and the beamline scientists at LS-CAT/Sector 21 at the Advanced Photon Source, Argonne National Laboratory, for their assistance. We also acknowledge support received from the Structural Biology Facility and the High Throughput Analysis Laboratory at Northwestern University. Funding was provided by the National Institutes of Health (NIH) grants R01 GM058443 and R35 GM118108 to A.M. C.W.C. was supported by the NIH Medical Scientist Training grant 4T32 GM008152, the Molecular Biophysics Training grant NIH 5T32 GM008382, and an Achievement Rewards for College Scientists Foundation Fellowship. LS-CAT/Sector 21 at the Advanced Photon Source, Argonne National Laboratory was supported by the Michigan Economic Development Corporation and the Michigan Technology Tri-Corridor. Support from the R.H. Lurie Comprehensive Cancer Center of Northwestern University to the Structural Biology Facility is acknowledged.

Received September 27, 2019; accepted December 12, 2019.

\section{REFERENCES}

Afonine PV, Grosse-Kunstleve RW, Echols N, Headd JJ, Moriarty NW, Mustyakimov M, Terwilliger TC, Urzhumtsev A, Zwart $\mathrm{PH}$,
Adams PD. 2012. Towards automated crystallographic structure refinement with phenix.refine. Acta Crystallogr D Biol Crystallogr 68: 352-367. doi:10.1107/S0907444912001308

Agirrezabala X, Valle M. 2015. Structural insights into tRNA dynamics on the ribosome. Int J Mol Sci 16: 9866-9895. doi:10.3390/ ijms16059866

Auffinger $P$, Westhof E. 2001. An extended structural signature for the tRNA anticodon loop. RNA 7: 334-341. doi:10.1017/ S1355838201002382

Bao L, Zhang X, Shi YZ, Wu YY, Tan ZJ. 2017. Understanding the relative flexibility of RNA and DNA duplexes: stretching and twiststretch coupling. Biophys J 112: 1094-1104. doi:10.1016/j.bpj .2017.02.022

Batey RT, Rambo RP, Doudna JA. 1999. Tertiary motifs in RNA structure and folding. Angew Chem Int Ed Engl 38: 2326-2343. doi:10 .1002/(SICI)1521-3773(19990816)38:16<2326::AID-ANIE2326>3 .0. $\mathrm{CO} ; 2-3$

Byrne RT, Konevega AL, Rodnina MV, Antson AA. 2010. The crystal structure of unmodified tRNA ${ }^{\text {Phe }}$ from Escherichia coli. Nucleic Acids Res 38: 4154-4162. doi:10.1093/nar/gkq133

Chan CW, Chetnani B, Mondragón A. 2013. Structure and function of the T-loop structural motif in noncoding RNAs. Wiley Interdiscip Rev RNA 4: 507-522. doi:10.1002/wrna.1175

Colussi TM, Costantino DA, Hammond JA, Ruehle GM, Nix JC, Kieft JS. 2014. The structural basis of transfer RNA mimicry and conformational plasticity by a viral RNA. Nature 511: 366-369. doi:10.1038/nature13378

Comarmond MB, Giegé R, Thierry JC, Moras D, Fischer J. 1986. Threedimensional structure of yeast tRNA ${ }^{\text {Asp }}$. I. Structure determination. Acta Cryst 42: 272-280. doi:10.1107/S0108768186098233

Dethoff EA, Chugh J, Mustoe AM, Al-Hashimi HM. 2012. Functional complexity and regulation through RNA dynamics. Nature 482: 322-330. doi:10.1038/nature10885

El Yacoubi B, Bailly M, de Crécy-Lagard V. 2012. Biosynthesis and function of posttranscriptional modifications of transfer RNAs. Annu Rev Genet 46: 69-95. doi:10.1146/annurev-genet-110711155641

Emsley P, Cowtan K. 2004. Coot: model-building tools for molecular graphics. Acta Crystallogr D Biol Crystallogr 60: 2126-2132. doi:10.1107/S0907444904019158

Evans PR, Murshudov GN. 2013. How good are my data and what is the resolution? Acta Crystallogr D Biol Crystallogr 69: 12041214. doi:10.1107/S0907444913000061

Fei J, Richard AC, Bronson JE, Gonzalez RL Jr. 2011. Transfer RNAmediated regulation of ribosome dynamics during protein synthesis. Nat Struct Mol Biol 18: 1043-1051. doi:10.1038/nsmb.2098

Fernández-Millán P, Schelcher C, Chihade J, Masquida B, Giege P, Sauter C. 2016. Transfer RNA: from pioneering crystallographic studies to contemporary tRNA biology. Arch Biochem Biophys 602: 95-105. doi:10.1016/j.abb.2016.03.005

Fulle S, Gohlke H. 2008. Analyzing the flexibility of RNA structures by constraint counting. Biophys J 94: 4202-4219. doi:10.1529/bio physj.107.113415

Giegé R, Frugier M. 2000-2013. Transfer RNA structure and identity. In Madame Curie Bioscience Database [Internet]. Landes Bioscience, Austin, TX. https://www.ncbi.nlm.nih.gov/books/NBK6236/

Hammond JA, Rambo RP, Filbin ME, Kieft JS. 2009. Comparison and functional implications of the 3D architectures of viral tRNA-like structures. RNA 15: 294-307. doi:10.1261/rna.1360709

Hammond JA, Rambo RP, Kieft JS. 2010. Multi-domain packing in the aminoacylatable $3^{\prime}$ end of a plant viral RNA. J Mol Biol 399: 450463. doi:10.1016/j.jmb.2010.04.016

Hendrix DK, Brenner SE, Holbrook SR. 2005. RNA structural motifs: building blocks of a modular biomolecule. Q Rev Biophys 38: 221-243. doi:10.1017/S0033583506004215 
Ishitani R, Nureki O, Nameki N, Okada N, Nishimura S, Yokoyama S. 2003. Alternative tertiary structure of tRNA for recognition by a posttranscriptional modification enzyme. Cell 113: 383-394. doi:10.1016/S0092-8674(03)00280-0

Juhling F, Morl M, Hartmann RK, Sprinzl M, Stadler PF, Putz J. 2009. tRNAdb 2009: compilation of tRNA sequences and tRNA genes. Nucleic Acids Res 37: D159-D162. doi:10.1093/nar/gkn772

Kabsch W. 2010. XDS. Acta Crystallogr D Biol Crystallogr 66: 125132. doi:10.1107/S0907444909047337

Karplus PA, Diederichs K. 2012. Linking crystallographic model and data quality. Science 336: 1030-1033. doi:10.1126/science.1218231

Kim SH, Suddath FL, Quigley GJ, McPherson A, Sussman JL, Wang AH, Seeman NC, Rich A. 1974. Three-dimensional tertiary structure of yeast phenylalanine transfer RNA. Science 185: 435440. doi:10.1126/science.185.4149.435

Kirchner S, Ignatova Z. 2015. Emerging roles of tRNA in adaptive translation, signalling dynamics and disease. Nat Rev Genet 16: 98-112. doi:10.1038/nrg3861

Korostelev A, Noller HF. 2007. The ribosome in focus: new structures bring new insights. Trends Biochem Sci 32: 434-441. doi:10.1016/ j.tibs.2007.08.002

Kuhn CD. 2016. RNA versatility governs tRNA function: why tRNA flexibility is essential beyond the translation cycle. Bioessays 38: 465473. doi:10.1002/bies.201500190

Lorenz C, Lünse CE, Mörl M. 2017. tRNA modifications: impact on structure and thermal adaptation. Biomolecules 7: E35. doi:10 $.3390 /$ biom7020035

Lu XJ, Olson WK. 2003. 3DNA: a software package for the analysis, rebuilding and visualization of three-dimensional nucleic acid structures. Nucleic Acids Res 31: 5108-5121. doi:10.1093/nar/gkg680

Lu XJ, Olson WK. 2008a. 3DNA: a versatile, integrated software system for the analysis, rebuilding and visualization of three-dimensional nucleic-acid structures. Nat Protoc 3: 1213-1227. doi:10 .1038/nprot.2008.104

Lu XJ, Olson WK. 2008b. 3DNA: a versatile, integrated software system for the analysis, rebuilding and visualization of three-dimensional nucleic-acid structures. Nat Protoc 3: 1213-1227. doi:10 .1038/nprot.2008.104

Lu XJ, Bussemaker HJ, Olson WK. 2015. DSSR: an integrated software tool for dissecting the spatial structure of RNA. Nucleic Acids Res 43: e142. doi:10.1093/nar/gkv716

Marín M, Fernández-Calero T, Ehrlich R. 2017. Protein folding and tRNA biology. Biophys Rev 9: 573-588. doi:10.1007/s12551017-0322-2

Milligan JF, Groebe DR, Witherell GW, Uhlenbeck OC. 1987. Oligoribonucleotide synthesis using T7 RNA polymerase and syn- thetic DNA templates. Nucleic Acids Res 15: 8783-8798. doi:10 .1093/nar/15.21.8783

Moore PB. 1999. Structural motifs in RNA. Annu Rev Biochem 68: 287-300. doi:10.1146/annurev.biochem.68.1.287

Murshudov GN, Vagin AA, Dodson EJ. 1997. Refinement of macromolecular structures by the maximum-likelihood method. Acta Crystallogr D Biol Crystallogr 53: 240-255. doi:10.1107/ S0907444996012255

Phizicky EM, Hopper AK. 2010. tRNA biology charges to the front. Genes Dev 24: 1832-1860. doi:10.1101/gad.1956510

Ramakrishnan V. 2002. Ribosome structure and the mechanism of translation. Cell 108: 557-572. doi:10.1016/S0092-8674(02) 00619-0

Robertson MP, Scott WG. 2008. A general method for phasing novel complex RNA crystal structures without heavy-atom derivatives. Acta Crystallogr D Biol Crystallogr D64: 738-744. doi:10.1107/ S0907444908011578

Robertus JD, Ladner JE, Finch JT, Rhodes D, Brown RS, Clark BF, Klug A. 1974. Structure of yeast phenylalanine tRNA at $3 \AA$ resolution. Nature 250: 546-551. doi:10.1038/250546a0

Roundtree IA, Evans ME, Pan T, He C. 2017. Dynamic RNA modifications in gene expression regulation. Cell 169: 1187-1200. doi:10 .1016/j.cell.2017.05.045

Shi H, Moore PB. 2000. The crystal structure of yeast phenylalanine tRNA at 1.93 A resolution: a classic structure revisited. RNA 6: 1091-1105. doi:10.1017/S1355838200000364

Stein N. 2008. CHAINSAW: a program for mutating pdb files used as templates in molecular replacement. J Appl Crystallogr 41: 641643. doi: $10.1107 /$ S0021889808006985

Sutton JL, Pollack L. 2015. Tuning RNA flexibility with helix length and junction sequence. Biophys J 109: 2644-2653. doi:10.1016/j.bpj .2015.10.039

Tickle IJ, Flensburg C, Keller P, Paciorek W, Sharff A, Vornhein C, Bricogne G. 2018. STARANISO. Global Phasing Ltd., Cambridge, UK.

Wang J. 2010. Inclusion of weak high-resolution X-ray data for improvement of a group II intron structure. Acta Crystallogr D Biol Crystallogr 66: 988-1000. doi:10.1107/S0907444910029938

Winn MD, Ballard CC, Cowtan KD, Dodson EJ, Emsley P, Evans PR, Keegan RM, Krissinel EB, Leslie AGW, McCoy A, et al. 2011. Overview of the CCP4 suite and current developments. Acta Crystallogr D 67: 235-242. doi:10.1107/S0907444910045749

Zhang XJ, Walker RC, Phizicky EM, Mathews DH. 2014. Influence of sequence and covalent modifications on yeast tRNA dynamics. J Chem Theory Comput 10: 3473-3483. doi:10.1021/ct500107y 

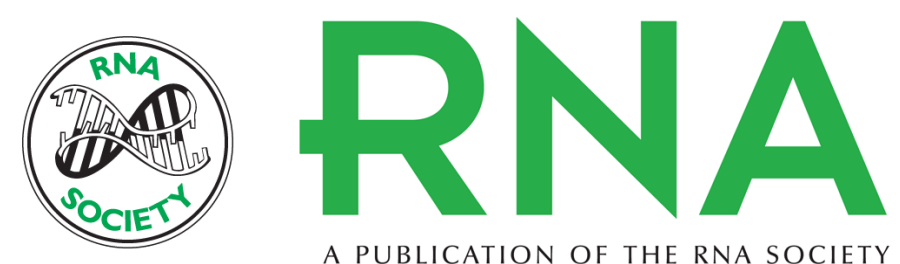

A PUBLICATION OF THE RNA SOCIETY

\section{Crystal structures of an unmodified bacterial tRNA reveal intrinsic structural flexibility and plasticity as general properties of unbound tRNAs}

Clarence W. Chan, Deanna Badong, Rakhi Rajan, et al.

RNA 2020 26: 278-289 originally published online December 17, 2019

Access the most recent version at doi:10.1261/rna.073478.119

Supplemental Material

References

Creative Commons License

Email Alerting Service
http://rnajournal.cshlp.org/content/suppl/2019/12/17/rna.073478.119.DC1

This article cites 47 articles, 6 of which can be accessed free at: http://rnajournal.cshlp.org/content/26/3/278.full.html\#ref-list-1

This article is distributed exclusively by the RNA Society for the first 12 months after the full-issue publication date (see http://rnajournal.cshlp.org/site/misc/terms.xhtml). After 12 months, it is available under a Creative Commons License (Attribution-NonCommercial 4.0 International), as described at http://creativecommons.org/licenses/by-nc/4.0/.

Receive free email alerts when new articles cite this article - sign up in the box at the top right corner of the article or click here.

To subscribe to RNA go to:

http://rnajournal.cshlp.org/subscriptions 